\title{
VARIOUS WAYS TO DETERMINE RATIONAL NUMBER SIZE: AN EXPLORATION ACROSS PRIMARY AND SECONDARY EDUCATION
}

\begin{abstract}
Understanding rational numbers is a complex task for primary and secondary school students. Previous research has shown that a possible reason is students' tendency to apply the properties of natural numbers (inappropriately) when they are working with rational numbers (a phenomenon called natural number bias). Focusing on rational number comparison tasks, recent research has shown that other incorrect strategies such as gap thinking or reverse bias can also explain these difficulties. The present study aims to investigate students' different ways of thinking when working on fraction and decimal comparison tasks. The participants were 1,262 primary and secondary school students. A TwoStep Cluster Analysis revealed six different student profiles according to their way of thinking. Results showed that while students' reasoning based on the properties of natural numbers decreased along primary and secondary school, almost disappearing at the end of secondary school, students' reasoning based on gap thinking increased along these grades. This result seems to indicate that when students overcome their reliance on natural numbers, they enter a stage of qualitatively different errors before finally reaching the stage of correct understanding.
\end{abstract}

Keywords: Rational numbers, fraction, natural number bias, gap thinking, reverse bias, profiles.

\section{INTRODUCTION}

Research has amply shown that a good understanding of rational numbers is an essential part of mathematical literacy, since it is required for learning more advanced mathematical contents such as algebra and calculus (Behr et al. 1983; Kieren 1992). However, the concept of rational number is one of the most complex to understand and master by students of primary and secondary education, and even adults show difficulties in understanding all its different aspects (Depaepe et al. 2018; Fischbein et al. 1985; Moss and Case 1999; Resnick et al. 1989; Torbeyns et al. 2015).

A frequently reported reason for students' difficulties with rational numbers is their inappropriate application of natural number properties (Moss 2005; Ni and Zhou 2005; Smith et al. 2005; Van Hoof et al. 2015). The tendency to do so is often denoted as natural number bias (Alibali and Sidney 2015; Van Dooren et al. 2015).

Before learning about rational numbers, students have already formed an initial concept of numbers, based on the act of counting (Vamvakoussi and Vosniadou 2004; Vosniadou et al. 2008). This number concept can be characterised as a natural number concept. When students are introduced to rational numbers, they do not necessarily leave this initial number concept completely behind. This latter concept frames students' interpretations of the new type of number that they are confronted with, and interferes in their learning, creating misconceptions that can last for years (Vamvakoussi and Vosniadou 2007). Clear evidence of the interference of natural numbers is the fact that students perform rational number tasks that are compatible with natural number knowledge more efficiently than tasks where such knowledge is 
incompatible (Nunes and Bryant 2008; Stafylidou and Vosniadou 2004). For example, if students are asked to anticipate the result of $5 \times 1 / 2$, they may be inclined to rely on the knowledge that multiplication always results in a larger number, leading them to think the result would be larger than 5 . If students are asked to anticipate the result of $5 \times 9 / 7$, they will correctly anticipate that it is larger than 5 .

Studies addressing the natural number bias phenomenon have considered three main domains in which rational numbers differ from natural numbers, causing difficulties for students: density of the rational number line, conducting operations with rational numbers, and determining rational number size (Gómez and Dartnell 2018; McMullen et al. 2015; Obersteiner et al. 2016; Vamvakoussi et al. 2018; Van Hoof et al. 2015). In addition, the diversity of symbolic notations relating to rational numbers can be considered to be a transversal difficulty across the previous domains (DeWolf and Vosniadou 2011).

The domain causing the most persistent difficulties is the density of rational numbers (Vamvakoussi and Vosniadou 2004; Vamvakoussi et al. 2011; Van Hoof et al. 2018). Unlike natural numbers, rational numbers are dense (there is an infinite amount of rational numbers between two other rational numbers, and it no longer makes sense to speak of the "next" number). Students often have difficulties in judging how many numbers there are between $3 / 5$ and $4 / 5$, believing that there are no numbers or considering that there is only 5/7 between 4/7 and 6/7 (Merenluoto and Lehtinen 2004). Regarding decimal representation, students tend to consider that there are no numbers between 1.67 and 1.68 , or that there is a finite number of decimal numbers (Moss and Case 1999). Combining density and representation of rational numbers, students sometimes believe that there can only be fractions between two fractions (either a finite or infinite number of fractions) but no decimals, and between two decimal numbers there can only be decimals (Vamvakoussi and Vosniadou 2004).

The second domain is related to arithmetic operations. When students start to encounter various arithmetic operations, they face combinations with natural numbers. At this point, they usually assume that addition and multiplication "always result in a larger number", and subtraction and division "always result in a smaller number" (Fischbein et al. 1985). From the moment rational numbers are introduced, this assumption is no longer valid. Studies have shown that students struggle with this idea until the end of secondary school (Van Hoof et al. 2015). Furthermore, fraction addition and subtraction also present numerous difficulties for students, especially in primary education. A common mistake consists of adding/subtracting both fractions' numerators and denominators (e.g. $1 / 3+2 / 6=3 / 9$ ), without taking into account the relation between numerator and denominator (Moss 2005; Streefland 1991). Regarding the adding or subtracting of decimal numbers, difficulties appear when the decimal part does not have the same number of digits (Hiebert and Wearne 1985).

In this study, we focused on the domain of the numbers size as previous research has shown that number size is the first key step in learners' understanding of rational numbers. We present a more extensive review of literature of this domain in the following section.

\section{THEORETICAL AND EMPIRICAL BACKGROUND}

\subsection{Natural number bias in numerical rational number size tasks}


Numerous studies have attempted to identify students' difficulties in determining the size of a fraction or a decimal number (McMullen et al. 2015; Meert et al. 2010; Stafylidou and Vosniadou 2004). In relation to fractions, an important factor is students' difficulty in understanding that fraction size cannot be determined by simply considering the numerators or denominators, as the size depends on the multiplicative relationship between its terms (Moss 2005; Ni and Zhou 2005; Smith et al. 2005). Students initially tend to interpret the symbol $a / b$ as two independent natural numbers separated by a slash (Mack 1995; Stafylidou and Vosniadou 2004), and do not consider the actual magnitude of the fraction.

Research focused on comparing fractions with a common component has found that students tend to correctly compare fractions with common denominators (e.g. $2 / 5$ vs. 4/5), but that they have greater difficulties in comparing fractions with common numerators (e.g. 5/9 vs. 5/7) (Gómez et al. 2015; Meert et al. 2010): they reason - based on the order of natural numbers - that the fraction with the larger components is also the larger fraction.

A similar phenomenon occurs when comparing fractions without common components. Students tend to think that a fraction is larger if the numerator and denominator are larger (Behr et al. 1984; Gelman et al. 1989; Resnick et al. 1989). Accordingly, they perform better on items where the largest fraction has the largest numerator and denominator (so-called congruent items, for example: $2 / 3$ vs. 7/9) than on items where the largest fraction has the smallest numerator and denominator (incongruent items, for example: 3/4 vs. 5/9). This has been shown to apply to elementary school-aged children (Meert et al. 2010), secondary school students (Van Hoof et al. 2013, 2015) and even adults (DeWolf and Vosniadou 2011; Obersteiner et al. 2013; Vamvakoussi et al. 2012).

As far as comparing decimal numbers is concerned, students tend to think that "longer decimals are larger" and "shorter decimals are smaller" (Moss 2005; Resnick et al. 1989), in line with the property that holds for natural numbers. For example, when asked which number is larger, 0.37 or 0.6 , most primary grade students claimed that 0.37 is larger, arguing that 37 is larger than 6 (Durkin and Rittle-Johnson 2015). Another important factor in these errors is the role of the zero. When a zero is in the tenths place, students often ignore it and treat the following digit as if it were in the tenths place (e.g. $0.07=0.7)$; they also consider that adding a 0 at the end of a decimal number increases its magnitude $(0.320$ is larger than 0.32) (Durkin and Rittle-Johnson 2015).

\subsection{Other ways of thinking about size}

In the previous section we discussed research that has indicated how students performed better on items comparing the size of rational numbers when they could apply the properties that held for natural numbers (congruent items) than in cases where those properties no longer held (incongruent items). These findings have been observed both for fractions (with and without common components) and for decimals. However, research results have not always pointed in the same direction. Studies with high performing students (Gómez et al. 2015) and with experts in mathematics (Barraza et al. 2017; DeWolf and Vosniadou 2015; Obersteiner and Alibali 2018; Obersteiner et al. 2013) have shown higher levels of accuracy in incongruent items than in congruent items, especially in the case of fraction comparison. This raises questions as to whether the natural number bias actually explains all errors and it highlights the 
need to consider further explanations involving, for instance, some of the commonly used strategies for comparing fractions (Gómez et al. 2017).

A widespread incorrect strategy adopted by students and adults in fraction comparison tasks consists in comparing the (absolute) difference between numerator and denominator in both fractions. This strategy is known as gap thinking (Pearn and Stephens 2004). According to this strategy, a fraction is considered larger than another fraction if the difference between the numerator and the denominator is smaller (e.g. $2 / 3$ is larger than $7 / 9$ "because from 2 to 3 there is a gap of one and from 7 to 9 there is a gap of two"). By applying this reasoning, students would consider that two fractions presenting the same gap are equal (e.g. $4 / 5$ is equal to $6 / 7$ "because both fractions have the same difference, just one gap") (Clarke and Roche 2009; Fazio et al. 2016; Moss 2005).

Recently, research has focused on examining whether the gap variable (difference between numerator and denominator) can explain why students achieve better results in incongruent fraction comparison tasks than in congruent ones. Gómez et al. (2017) conducted a study with undergraduate Engineering students who performed 180 fraction comparisons involving congruent and incongruent fraction pairs with and without common components. These authors manipulated the gap variable, distinguishing between items where gap thinking led to a correct answer (e.g. 5/8 vs. 2/7 - gap thinking correct), items where gap thinking led to an incorrect answer (e.g. 1/3 vs. 4/7 - gap thinking incorrect), and items where gap thinking was uninformative (e.g. 2/3 vs. 7/8 - gap thinking neutral).

The results showed that in the case of items without common components, undergraduate students performed better in incongruent items than in congruent ones. González-Forte et al. (2018) found that primary and secondary school students from each grade were more successful in the case of natural number congruent items than incongruent items, but differences in $8^{\text {th }}$ and $9^{\text {th }}$ grade between both kinds of items were the smallest. A qualitative analysis of students' justifications showed that gap thinking reasoning notably emerged in $8^{\text {th }}$ and $9^{\text {th }}$ grade, while it was much less present in previous grades. The increase in the use of this type of reasoning and the decrease of natural number-based reasoning could explain why differences in students' success levels between congruent and incongruent items were smaller in $8^{\text {th }}$ and $9^{\text {th }}$ grade. Therefore, as the study of Gómez et al. (2017) concluded, gap thinking seems to influence differences between students' levels of achievement regarding congruent and incongruent items.

The literature points to a third incorrect type of reasoning: students have been reported to think contrary to the natural number bias, considering that the largest fraction is the fraction with the smallest numerator, denominator or both (DeWolf and Vosniadou 2015; Fazio et al. 2016; Gómez and Dartnell 2018; Rinne et al. 2017). In this kind of reasoning, hereon reverse bias, students focus their attention on the size of each fraction's components, considering that "the smaller components, the larger fraction" (DeWolf and Vosniadou 2015, p. 9). Based on this reasoning, students can correctly solve the incongruent items, but will incorrectly solve the congruent ones, showing an effect that is contrary to that of the natural number bias. This kind of reasoning may also explain the results of some previous studies where a better performance was found regarding incongruent items than congruent items (DeWolf and Vosniadou 2011, 2015; Obersteiner et al. 2013). Current research has taken into account these alternative ways of thinking 
about the size of fractions, having been observed in primary and secondary school students (Gómez and Dartnell 2018; Rinne et al. 2017), and in adults (Barraza et al. 2017; Fazio et al. 2016; Obersteiner and Alibali 2018).

Considering the existence of students' different ways of thinking about fraction comparison, research has been conducted on determining student profiles according to their solutions to different kinds of items. Gómez and Dartnell (2018) carried out a study with $5^{\text {th }}, 6^{\text {th }}$ and $7^{\text {th }}$ grade students, in which reaction times and accuracy were measured against congruent/incongruent items and with/without common components. They identified six student profiles according to the characteristics of their answers. In addition to a subgroup of students that were high achievers across all types of items, a subgroup of students presented a natural number ordering bias; a subgroup of students reasoned based on the ordering of natural numbers only in the case of items with common components; a subgroup of students had a high level of accuracy, except in the case of congruent items without common components; another subgroup of students showed a behaviour contrary to that of the natural number bias; and finally, a subgroup of students presented low accuracy percentages across all items.

Taken as a whole, over the last decade, many studies have indicated that in addition to the natural number bias, various kinds of other incorrect reasoning occur when students compare rational number magnitudes. Our study takes this research line a step further by conducting a cross-sectional analysis across a broad range of ages (primary as well as secondary education), to examine the different ways of thinking about fraction magnitude and the evolution of this thinking at different ages.

\subsection{The present study}

The aim of the present study is to investigate how Spanish primary and secondary school students compare the magnitudes of two fractions or two decimal numbers as well as the kinds of incorrect reasoning they engage in. A total of 31 items of comparison of rational numbers were given to them. Two conditions were taken into account: the congruence or incongruence with natural number ordering (congruency) and the gap -only for fractions- between the numerator and the denominator (gap). In this sense, this study intended to extend the results obtained by Gómez and Dartnell (2018) in their cluster analysis by including the gap condition and decimal number comparisons. Furthermore, we included a wide age range (from $5^{\text {th }}$ to $10^{\text {th }}$ grade) since the majority of the previous studies had shown that older students obtained opposite results regarding congruency (Barraza et al. 2017; DeWolf and Vosniadou 2015; Obersteiner and Alibali 2018).

By conducting this study over a wider age range, and by including an extended set of items (decimals and fractions, we well as manipulating both natural number congruency and gap), it was possible to examine learner profiles according to the understanding of rational number size, verify which profiles were predominant, and how they evolved across grades throughout the curriculum at the ages where rational number instruction takes place. Our basic hypothesis was that students would not simply transition from a natural number biased idea of rational number size to a correct understanding, but that various qualitatively different ways of understanding would appear that could be considered as intermediate stages between a natural number bias idea and a correct understanding. 


\section{METHOD}

\subsection{Participants}

The participants were 1,262 primary and secondary school students from 10 different Spanish schools (five primary schools and five secondary schools). The sample was distributed across $5^{\text {th }}$ grade $(n=205)$, $6^{\text {th }}$ grade $(n=219), 7^{\text {th }}$ grade $(n=221), 8^{\text {th }}$ grade $(n=209), 9^{\text {th }}$ grade $(n=198)$, and $10^{\text {th }}$ grade $(n=210)$. Approximately the same number of boys and girls participated in the study. They came from mixed socioeconomic backgrounds.

\subsection{Instrument and procedure}

The instrument was elaborated based on the "size" items of the RNST (Rational Number Sense Test), as developed and validated by Van Hoof et al. (2015). The test contains 31 comparison items: 25 fraction items and 6 decimal items.

We developed additional parallel items taking into account the congruence with respect to the ordering of natural numbers, proposing 18 congruent items (those in which natural number knowledge leads to the correct answer: e.g. $5 / 8$ vs. $2 / 7$ and 4.4 vs. 4.50 ) and 13 incongruent items (those in which natural number knowledge leads to the wrong answer: e.g. $2 / 3$ vs. $3 / 7$ and 0.36 vs. 0.5 ). For the fraction items, the instrument consisted of 10 items with common components (e.g. 3/8 vs. 5/8) - 5 congruent and 5 incongruent - and 15 items without common components (e.g. 5/8 vs. 2/7) - 10 congruent and 5 incongruent. In addition, the gap condition (difference between numerator and denominator) was manipulated in the fraction comparison items without common components: we thus proposed 5 congruent items where gap thinking led to the correct answer (e.g. 1/7 vs. 4/9), 5 incongruent items where gap thinking led to the correct answer (e.g. $2 / 3$ vs. 3/7) and 5 congruent items where gap thinking led to the incorrect answer (e.g. 5/9 vs. 1/3). See Table 1 for the subset of comparison items used. As shown, incongruent items without common components where gap thinking led to the incorrect answer were not included, since it is impossible to create proper fraction pairs that meet those conditions.

Table 1 Comparison items used in the test

\begin{tabular}{|c|c|c|c|c|}
\hline & \multicolumn{3}{|c|}{ Fraction } & \multirow[t]{2}{*}{ Decimal } \\
\hline & \multirow{2}{*}{\multicolumn{2}{|c|}{$\begin{array}{c}\text { Common components } \\
\text { Gap thinking correct }\end{array}$}} & ommon components & \\
\hline & & & \multicolumn{2}{|l|}{ Gap thinking incorrect } \\
\hline \multirow[t]{5}{*}{ Congruent } & $3 / 8$ vs. $5 / 8$ & $5 / 8$ vs. $2 / 7$ & $1 / 3$ vs. $5 / 8$ & 0.400 vs. 0.25 \\
\hline & $4 / 9$ vs. $7 / 9$ & $5 / 7$ vs. $2 / 5$ & $2 / 3$ vs. $7 / 9$ & 4.4 vs. 4.50 \\
\hline & $1 / 7$ vs. $3 / 7$ & $3 / 7$ vs. $7 / 9$ & $4 / 7$ vs. $1 / 3$ & 5.3 vs. 5.7 \\
\hline & $3 / 7$ vs. $5 / 7$ & $1 / 7$ vs. $4 / 9$ & $5 / 9$ vs. $1 / 3$ & \\
\hline & $2 / 5$ vs. $4 / 5$ & $7 / 9$ vs. $4 / 7$ & $2 / 3$ vs. $7 / 9^{1}$ & \\
\hline \multirow[t]{5}{*}{ Incongruent } & $3 / 8$ vs. $3 / 4$ & $2 / 3$ vs. $3 / 7$ & - & 0.36 vs. 0.5 \\
\hline & $2 / 5$ vs. $2 / 9$ & $4 / 7$ vs. $3 / 4$ & - & 0.3 vs. 0.30 \\
\hline & $1 / 7$ vs. $1 / 4$ & $5 / 9$ vs. $2 / 3$ & - & 2.621 vs. 2.0621 \\
\hline & $4 / 5$ vs. $4 / 7$ & $4 / 9$ vs. $3 / 5$ & - & \\
\hline & $5 / 6$ vs. $5 / 9$ & $4 / 5$ vs. $5 / 8$ & - & \\
\hline
\end{tabular}

\footnotetext{
${ }^{1}$ Item $2 / 3$ vs. $7 / 9$ appears twice in the test. Since items are randomly presented in two separated blocks and in 8 versions with different orders, it seems impossible for students to realize that this item appeared a second time.
} 
In the congruent items where gap thinking led to the correct answer, if students used a reasoning based on the natural number bias "fraction is larger if numerator and denominator are larger", students could obtain a correct answer; and if students used the gap thinking "fraction is larger if the difference between numerator and denominator is smaller", they would also have obtained a correct answer. In the case of congruent items where gap thinking led to an incorrect answer, if students reasoned based on natural number bias, students would give a correct answer. Nevertheless, if students used gap thinking, they would produce an incorrect answer. Finally, in the case of incongruent items where gap thinking led to the correct answer, if students reasoned based on natural number bias, they would give an incorrect answer but if they used gap thinking, they would produce a correct answer.

Eight different versions of the test were developed, each randomly presenting the students with 31 items in two separated blocks. Students were asked to individually solve these two paper-and-pencil tests (the two separated blocks with these 31 items) during a mathematics lesson at school. The data were collected during the spring of 2018. Participants (and schools) were recruited randomly and parental consent was obtained for all of them. No time limit was used, as a time limitation could encourage natural number biased reasoning (Vamvakoussi et al. 2012).

\subsection{Analysis}

First, the students' answers were coded based on whether the answer marked was correct (1) or incorrect (0). Second, these data were analysed to find possible qualitatively similar response patterns among students, using a TwoStep Cluster Analysis. This analysis, developed by Chiu et al. (2001), copes effectively with very large datasets. The algorithm is based on a two-stage approach. In the first stage, the algorithm undertakes a procedure that is very similar to the k-means algorithm. Based on these results, during the second stage, the procedure follows a modified hierarchical agglomerative clustering process that combines the objects sequentially so as to form homogenous clusters. The procedure can handle categorical and continuous variables simultaneously; it offers users the flexibility to specify the cluster numbers as well as the maximum number of clusters, or to opt for the automatic choice of number of clusters based on statistical evaluation criteria. Moreover, the procedure guides decision-making regarding the number of clusters to retain from the data, by calculating measures of fit such as the Akaike Information Criterion (AIC) or Bayesian Information Criterion (BIC) (Sarstedt and Mooi 2004). The statistical software used was SPSS version 25.

The analysis was carried out taking into account the means of 7 types of items: congruent items of fractions with common components $(F C C C)$, incongruent items of fractions with common components (FICC); congruent items of fractions without common components where gap thinking leads to the correct answer $(F C W C C G C)$; congruent items of fractions without common components where gap thinking leads to the incorrect answer (FCWCCGI); incongruent items of fractions without common components where gap thinking leads to a correct answer (FIWCC); congruent items of decimal numbers $(D C)$; and incongruent items of decimal numbers $(D I)$.

Although we used correct or incorrect answer coding to conduct the study, a cluster analysis using these seven types of items gave us some indication of students' types of reasoning. For example, if a student 
was highly accurate regarding the congruent items (FCCC, FCWCCGC, FCWCCGI, DC) independently of the gap condition but incorrectly solved incongruent items, we could indirectly deduce that this student's reasoning was based on a natural number bias. If a student incorrectly solved items where gap thinking led to an incorrect answer (FCWCCGI) but the student presented a high level of accuracy for the rest of the items, we could indirectly deduce that this student's reasoning was based on gap thinking. Naturally, this approach did not allow us to directly observe the verbalising of the type of reasoning. The deduction was indirect, based on quantitative differences in performance across a range of items in which the item characteristics had been manipulated.

\section{RESULTS}

As a result of the TwoStep Cluster Analysis, we chose to work with six student profiles. This decision was based on a low BIC value (see Table 2) and also on an interpretation point of view. BIC value indicates an optimal balance between the model's fit and the model's complexity in terms of the number of estimated parameters $(=\mathrm{fp})$. This value is calculated as follows: $\mathrm{BIC}=-2 \log \mathrm{L}+\log (\mathrm{I}) \times \mathrm{fp}$. Schwarz (1978) proposed the BIC criterion, which takes the sample size into account. Due to the large sample size shown, we chose this value (Van Hoof et al. 2018).

The six-state model was also preferred from an interpretation point of view. As shown in Fig. 1 (that displays the mean accuracy scores on all subtests per profile, in the five-, six-, and seven-class solution), the additional profile (represented with circles) that appeared in the six-class solution compared to the five-class solution was theoretically interesting, because it allows to differentiate between learners who tend to rely on natural number knowledge in fractions but not in decimals (mean accuracy in incongruent items with fractions: $12 \%$, mean accuracy in incongruent items with decimals: $89 \%$ ), and learners who show natural number-based reasoning both in fractions and in decimals (mean accuracy in incongruent items with fractions: 5\%, mean accuracy in incongruent items with decimals: $33 \%$ ). In contrast, the additional profile that appeared in the seven-class solution (represented with plus signs) was theoretically not very interesting, since it only distinguished between a group of learners presenting very low accuracy for fraction comparison items where gap thinking was incorrect, and a group with low accuracy for those items and average accuracy for decimal comparison items.

Table 2 Fit measures of the three- to seven-state solution

\begin{tabular}{ccccc}
\hline $\begin{array}{c}\text { Number of } \\
\text { Clusters }\end{array}$ & $\begin{array}{c}\text { Schwarz's Bayesian } \\
\text { Criterion (BIC) }\end{array}$ & $\begin{array}{c}\text { BIC } \\
\text { Change }\end{array}$ & $\begin{array}{c}\text { Ratio of BIC } \\
\text { Changes }\end{array}$ & $\begin{array}{c}\text { Ratio of Distance } \\
\text { Measures }\end{array}$ \\
\hline 3 & 4010.103 & -969.391 & .782 & 2.082 \\
4 & 3596.556 & -413.547 & .333 & 1.587 \\
5 & 3372.957 & -223.598 & .180 & 1.214 \\
6 & 3206.450 & -166.507 & .134 & 1.271 \\
7 & 3096.827 & -109.622 & .088 & 1.398 \\
\hline
\end{tabular}



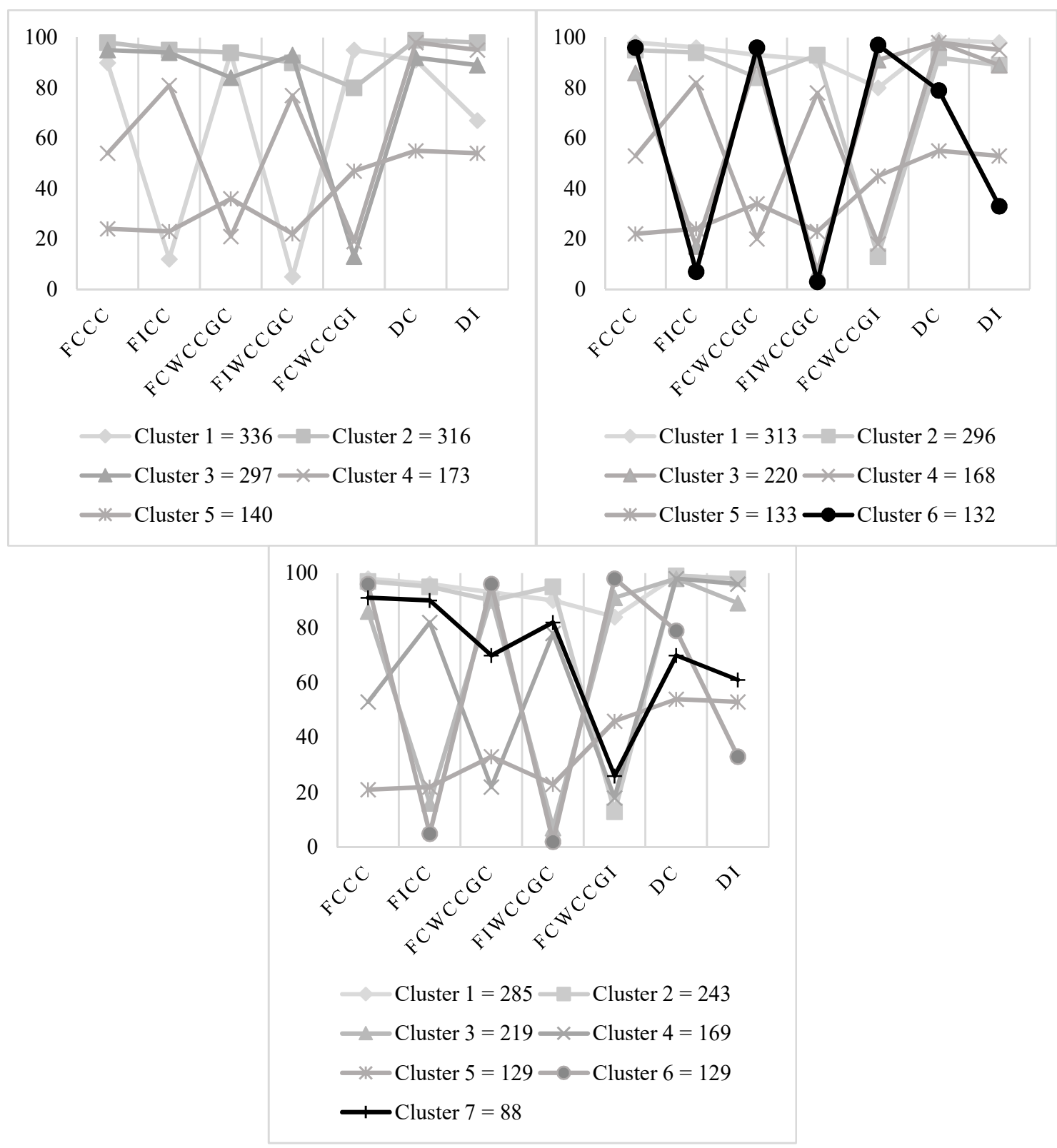

Fig. 1 Profiles in the five, six, and seven-class solution, with mean accuracy scores on every subtest and number of students per cluster

\subsection{Identified profiles}

We named the obtained profiles (Fig. 2) as follow: All Correct, Gap Thinker, Fraction NNB, Full NNB, Reverse Bias and Remainder. Below, we describe the six profiles and the percentage of students in each profile.

- All Correct $(24.8 \%, n=313)$ : students who answered all or nearly all (more than $90 \%$ ) items correctly, demonstrating that they mastered the domain of rational number size, both in fractions and decimals, and were not affected by gap thinking or that of natural number ordering of rational number components. 
- Full NNB (10.5\%, $n=132)$ : students who incorrectly solved (nearly) all the incongruent items, both for fractions and for decimal numbers. In contrast, their accuracy was very high regarding congruent items. These students solved (nearly) all the items according to the natural number bias, based on the ordering of the natural numbers to determine the size of a fraction and on the length of the decimal part to determine the size of the decimal numbers.

- Fraction $N N B(17.4 \%, n=220)$ : students who had difficulties in the incongruent fraction comparison items, both with common components and without common components. These students based their answers on natural number ordering to determine the size of the fractions and correctly solved the items where this knowledge allowed to solve them (items where the largest fraction had the largest numerator and denominator), and incorrectly solved items where natural number knowledge was not compatible (the largest fraction had the smallest numerator and denominator). However, they correctly solved both congruent and incongruent decimal items.

- Gap Thinker $(23.5 \%, n=296)$ : students who showed difficulties only in the items in which gap thinking led to an incorrect answer, solving the rest of the items correctly (congruent and incongruent items with common components and without common components). These students did not base their answers on the ordering of natural numbers to determine the size of a fraction. They based them on the difference between the numerator and the denominator (the smaller the difference, the larger the magnitude). In relation to the decimal numbers, they did not seem to have difficulties in either congruent or incongruent items.

- Reverse Bias $(13.3 \%, n=168)$ : students who showed difficulties specifically in congruent fraction items - where knowledge of natural number ordering would facilitate the solving - and correctly solved the incongruent items. These students used a reasoning contrary to the natural number bias, that is, they considered the fraction with the smallest denominator to be the largest fraction. As far as decimal numbers were concerned, they did not seem to have difficulties in either congruent or incongruent items.

- Remainder $(10.5 \%, n=133)$ : students with a generally low performance, but who solved the items without any identifiable pattern. 


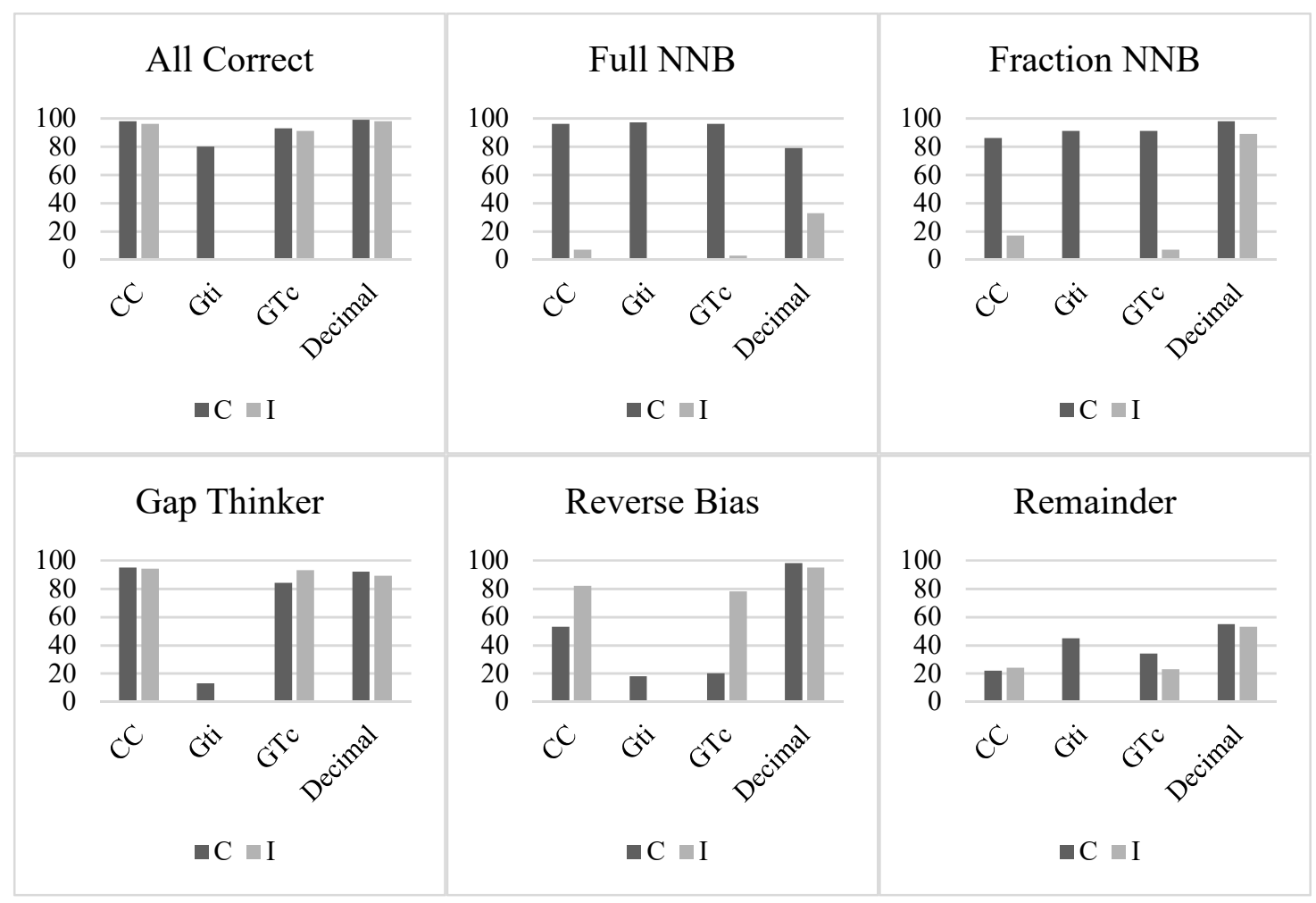

Fig. 2 Characteristics of students' profiles

$C C$ corresponds to the fraction items with common components, GTi to the fraction items without common components where gap thinking led to the incorrect answer, GTc to the fraction items without common components where gap thinking led to the correct answer; and Decimal to the decimal number items.

\subsection{Evolution of the profiles by grade}

In terms of evolution (Fig. 3), a first observation is that the percentage of students belonging to the All Correct group was higher in the last grades $\left(10.7 \%\right.$ in $5^{\text {th }}$ grade and $38.6 \%$ in $10^{\text {th }}$ grade). A logistic regression analysis showed a significant main effect of grade for the All Correct group $\chi^{2}(5, N=1262)=$ 50.615, $p<0.001$. Therefore, older students performed better in fraction and decimal comparison. However, most students did not reach this profile even in $10^{\text {th }}$ grade. Second, the percentage of the Full $N N B$ group was higher during the first years, and almost disappeared by the end of secondary school $\left(21.5 \%\right.$ in $5^{\text {th }}$ grade and $3.3 \%$ in $10^{\text {th }}$ grade). Third, the percentage of the Fraction NNB group was also lower in the last grades, but did not disappear at the end of secondary school $\left(26.8 \%\right.$ in $5^{\text {th }}$ grade and $10.0 \%$ in $10^{\text {th }}$ grade). This led us to consider that by the end of secondary school, the natural number bias no longer appeared in items with decimals while it was still observable for fraction items. The statistical analysis also showed a significant grade effect for both groups $\chi^{2}(5, N=1262)=46.586, p<0.001$ and $\chi^{2}(5, N=1262)=27.139, p<0.001$, respectively. 


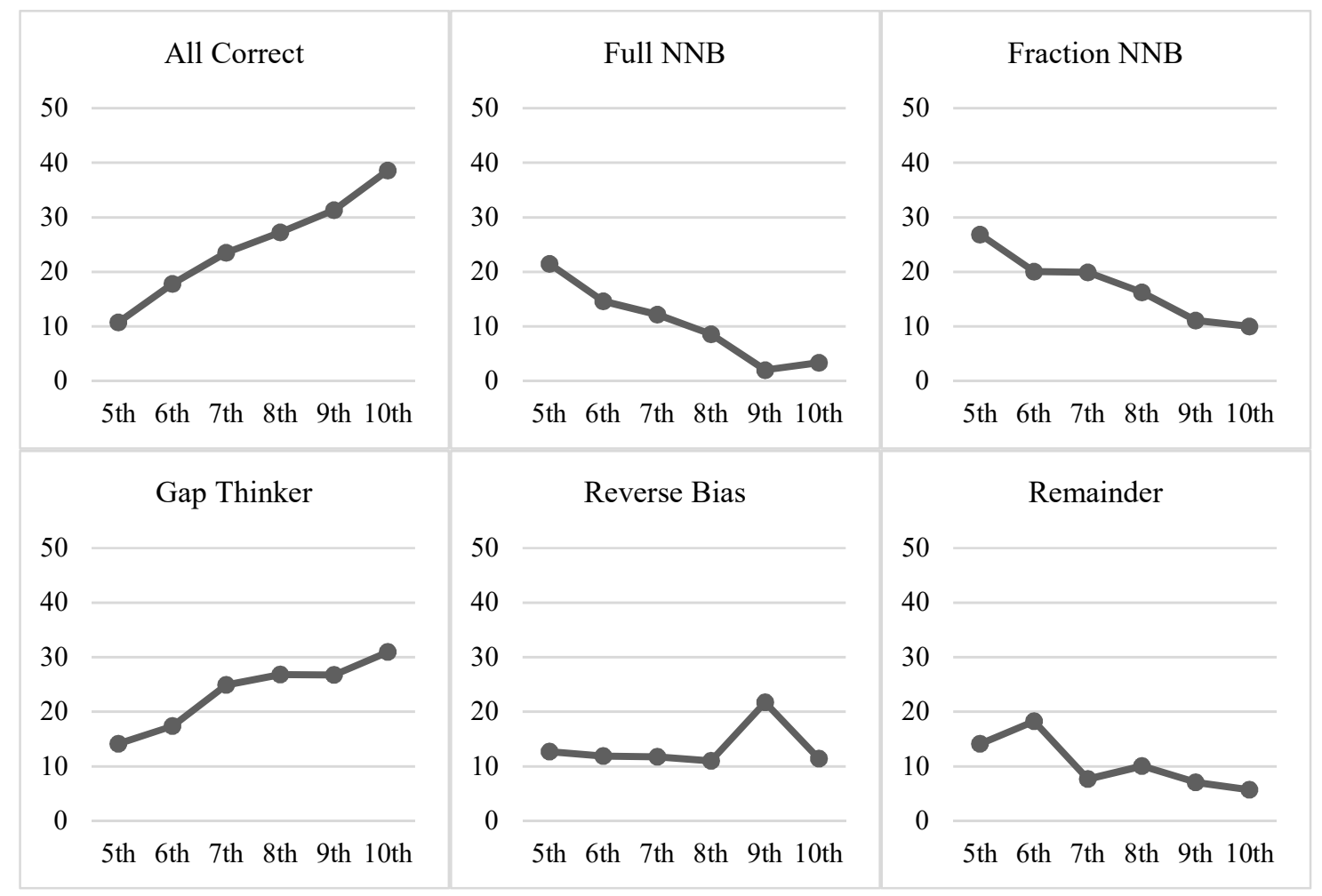

Fig. 3 Evolution of the profiles from $5^{\text {th }}$ to $10^{\text {th }}$ grade

The percentage of the Gap Thinkers group was considerably higher in the last grades $\left(14.1 \%\right.$ in $5^{\text {th }}$ grade and $31.0 \%$ in $10^{\text {th }}$ grade). The logistic regression analysis showed a significant grade effect in the Gap thinker group $\chi^{2}(5, N=1262)=23.096, p<0.001$. From $8^{\text {th }}$ grade on, gap thinking was used more frequently than natural number order-based reasoning. This result seems to indicate that in the last years of secondary school $\left(8^{\text {th }}, 9^{\text {th }}\right.$ and $10^{\text {th }}$ grade), students tended to rely on the idea that the difference ( gap) between numerator and denominator determined the fraction size. Regarding the Reverse Bias profile, results showed a constant trend (approximately $10 \%$ of students in each grade used this reasoning), except in $9^{\text {th }}$ grade, where the percentage was considerably higher than in the other grades (21.7\%). A significant grade effect was also obtained for this group, $\chi^{2}(5, N=1262)=14.173, p<0.015$. It thus seems that the reasoning "if the denominator is smaller, the fraction is larger", was present throughout all the grades. Finally, the percentage of Remainder profile students was small throughout all grades, and slightly smaller in the last years $\left(14.1 \%\right.$ in $5^{\text {th }}$ grade and $5.7 \%$ in $10^{\text {th }}$ grade). The analysis showed also a significant grade effect $\chi^{2}(5, N=1262)=24.824, p<0.001$.

These results indicate that although the use of natural number order-based reasoning is smaller in the last years of secondary school and the percentage of students with an All Correct profile is higher, there is also a constant use of reverse bias strategy in all grades (with an increase between $8^{\text {th }}$ and $9^{\text {th }}$ grade) and a higher use of a reasoning based on the difference between numerator and denominator (gap thinking) during the last grades of secondary education.

\section{DISCUSSION AND CONCLUSIONS}


A cross-sectional study was carried out with a large sample of students taken from the last grades of primary school to the last grades of secondary school. Using a TwoStep Cluster Analysis, we documented students' different ways of thinking about rational number size: students whose reasoning was based on their natural number knowledge (Full $N N B$ and Fraction NNB profiles), students whose reasoning was based on the difference between numerator and denominator (Gap Thinker profile), students whose reasoning was based on the smaller denominator size (Reverse Bias profile), and students whose reasoning showed an understanding of the rational number size (All Correct profile). This result extends previous research in two different ways. On the one hand, it characterises different students' incorrect ways of thinking in primary and secondary school, extending the profiles obtained by Gómez and Dartnell (2018) with fifth, sixth and seventh grade students from Chile. On the other hand, we examined the evolution of the different ways of thinking (profiles) from fifth to tenth grade.

As in the study of Gómez and Dartnell (2018), the current study identified six student profiles. The All Correct profile corresponded to the subgroup of high achievers across all types of items in their study. Full $N N B$ and Fraction $N N B$ profiles corresponded to students biased by natural number ordering knowledge. The first was biased regarding fractions and decimals, and the second only concerning fractions. Gómez and Dartnell (2018) took into account only fraction items, obtaining two subgroups of students: students biased regarding items with common components and students biased regarding both items with common components and without common components. In our study, NNB students were biased due to their natural number knowledge both regarding items with common components and without common components. The Reverse Bias profile included students who considered that the largest fraction was the fraction with the smallest denominator (DeWolf and Vosniadou 2015; Fazio et al. 2016; Rinne et al. 2017). This profile corresponded to a subgroup of students who showed a behaviour contrary to the natural number bias in Gómez and Dartnell's study, solving the incongruent items better than the congruent ones. Remainder corresponded to the group of students who answered all items with a low degree of accuracy.

Nevertheless, Gómez and Dartnell (2018) found a group of learners who answered congruent items without common components incorrectly. In our study, having taken the gap condition into account, we obtained the Gap Thinker profile: students who answered correctly only the items where gap thinking led to the correct answer. Therefore, it was possible that in the Gómez and Dartnell study, the items used were congruent with natural number ordering, but gap thinking led to an incorrect answer.

The students' profiles obtained in the present study extend previous research on natural number bias, since the existence of other incorrect ways of thinking, such as gap thinking and reverse bias, indicates that the phenomenon of natural number bias is not the sole explanation for primary and secondary school students' difficulties in determining rational number size. In that sense, our results could explain the controversial results obtained in previous research, where incongruent items obtained higher levels of accuracy than congruent ones (Barraza et al. 2017; DeWolf and Vosniadou 2015; Gómez et al. 2015; Obersteiner and Alibali 2018; Obersteiner et al. 2013).

Finally, our results provide information about the evolution of the different ways of thinking from $5^{\text {th }}$ to $10^{\text {th }}$ grade, suggesting that students change the ways of thinking along these grades. Natural number bias 
reasoning (Full $N N B$ and Fraction $N N B$ ) is the predominant way of thinking in $5^{\text {th }}$ and $6^{\text {th }}$ grade. An explanation is that students' first contact with rational numbers is in $3^{\text {rd }}$ grade, therefore in primary school, students build solid knowledge of natural numbers. Despite the fact that it is the most predominant way of thinking in primary education, its use decreases over the following grades, almost disappearing at the end of secondary education with decimal numbers. This decrease corresponds to an increase in correct reasoning along grades but also to an increase in other incorrect reasoning: gap thinking and reverse bias (this latter reasoning appearing between $8^{\text {th }}$ and $9^{\text {th }}$ grade). This result seems to indicate that when a reliance on natural number thinking is overcome, it is followed by qualitatively different errors before reaching the stage of correct understanding.

\section{Acknowledgments}

This research was carried out with the support of Conselleria d'Educació, Investigació, Cultura i Esport (Generalitat Valenciana, Spain) (PROMETEO/2017/135) and with the support of University of Alicante (UAFPU2018-035).

\section{REFERENCES}

Alibali, M. W., \& Sidney, P. G. (2015). Variability in the natural number bias: Who, when, how, and why. Learning and Instruction, 37, 56-61. https://doi.org/10.1016/j.learninstruc.2015.01.003

Barraza, P., Avaria, R., \& Leiva, I. (2017). The role of attentional networks in the access to the numerical magnitude of fractions in adults/El rol de las redes atencionales en el acceso a la magnitud numérica de fracciones en adultos. Estudios de Psicología,38(2), 495-522. https://doi.org/10.1080/02109395.2017.1295575

Behr, M. J., Lesh, R., Post, T., \& Silver E. (1983). Rational Number Concepts. In R. Lesh, \& M. Landau (Eds.), Acquisition of Mathematics Concepts and Processes, (pp. 91-125). New York: Academic Press.

Behr, M. J., Wachsmuth, I., Post, T. R., \& Lesh, R. (1984). Order and equivalence: A clinical teaching experiment. Journal of Research in Mathematics Education, 15(5), 323-341.

Chiu, T., Fang, D., Chen, J., Wang, Y., \& Jeris, C. (2001). A robust and scalable clustering algorithm for mixed type attributes in large database environment. In Proceedings of the seventh ACM SIGKDD International Conference on Knowledge Discovery and Data Mining (pp. 263-268). ACM. https://doi.org/10.1145/502512.502549

Clarke, D. M., \& Roche, A. (2009). Students' fraction comparison strategies as a window into robust understanding and possible pointers for instruction. Educational Studies in Mathematics, 72(1), 127-138. https://doi.org/10.1007/s10649-009-9198-9

Depaepe, F., Van Roy, P., Torbeyns, J., Kleickmann, T., Van Dooren, W., \& Verschaffel, L. (2018). Stimulating pre-service teachers' content and pedagogical content knowledge on rational numbers. Educational Studies in Mathematics, 99(2), 197-216. https://doi.org/10.1007/s10649018-9822-7

DeWolf, M., \& Vosniadou, S. (2011). The whole number bias in fraction magnitude comparisons with adults. In L. Carlson, C. Hoelscher, \& T. F. Shipley (Eds.), Proceedings of the 33rd annual 
conference of the cognitive science society (pp. 1751-1756). Austin, TX: Cognitive Science Society.

DeWolf, M., \& Vosniadou, S. (2015). The representation of fraction magnitudes and the whole number bias reconsidered. Learning and 39-49. https://doi.org/10.1016/j.learninstruc.2014.07.002

Durkin, K., \& Rittle-Johnson, B. (2015). Diagnosing misconceptions: Revealing changing decimal fraction knowledge. Learning and $\quad$ Instruction, 37, https://doi.org/10.1016/j.learninstruc.2014.08.003

Fazio, L. K., DeWolf, M., \& Siegler, R. S. (2016). Strategy use and strategy choice in fraction magnitude comparison. Journal of Experimental Psychology: Learning, Memory, and Cognition, 42(1), 116. https://doi.org/10.1037/xlm0000153

Fischbein, E., Deri, M., Nello, M. S., \& Marino, M. S. (1985). The role of implicit models in solving verbal problems in multiplication and division. Journal for Research in Mathematics Education, 16, 3-17. https://doi.org/10.2307/748969

Gelman, R., Cohen, M., \& Hartnett, P. (1989). To know mathematics is to go beyond thinking that “fractions aren't numbers”. In C. Maher, G. Goldin, \& R. Davis (Eds.), Proceedings of the eleventh annual meeting of North American Chapter of the International Group for the Psychology of Mathematics Education (Vol. 2, pp. 29-67). New Brunswick, NJ: Center for Mathematics, Science, and Computer Education at Rutgers-The State University of New Jersey.

Gómez, D., \& Dartnell, P. (2018). Middle schoolers' biases and strategies in a fraction comparison task. International Journal of Science and Mathematics Education, 17(6), 1233-1250. https://doi.org/10.1007/s10763-018-9913-Z

Gómez, D., Jiménez, A., Bobadilla, R., Reyes, C., \& Dartnell, P. (2015). The effect of inhibitory control on general mathematics achievement and fraction comparison in middle school children. ZDM, 47(5), 801-811. https://doi.org/10.1007/s11858-015-0685-4

Gómez, D., Silva, E., \& Dartnell, P. (2017). Mind the gap: congruency and gap effects in engineering students' fraction comparison. In B. Kaur, W. K. Ho, T. L. Toh, \& B. H. Choy (Eds.), Proceedings of the 41 st Conference of the International Group for the Psychology of Mathematics Education (Vol. 2, pp. 353-360). Singapore: PME.

González-Forte, J.M., Fernández, C., \& Van Dooren, W. (2018). Gap and congruency effect in fraction comparison. In E. Bergqvist, M. Österholm, C. Granberg, \& L. Sumpter (Eds.), Proceedings of the 42nd Conference of the International Group for the Psychology of Mathematics Education (Vol. 2, pp. 459-466). Umeå, Sweden: PME.

Hiebert, J., \& Wearne, D. (1985). A model of students' decimal computation procedures. Cognition and Instruction, 2(3-4), 175-205. https://doi.org/10.1080/07370008.1985.9648916

Kieren, T. E. (1992). Rational and fractional numbers as mathematical and personal knowledge: Implications for curriculum and instruction. In G. Leinhardt, R. Putnam, \& R. Hattrup (Eds.), Analysis of arithmetic for mathematics teaching (pp. 323-372). Hillsdale, NJ, USA: Lawrence Erlbaum. 
Mack, N. K. (1995). Confounding whole-number and fraction concepts when building on informal knowledge. Journal for Research in Mathematics Education, 26, 422-441. https://doi.org/10.2307/749431

McMullen, J., Laakkonen, E., Hannula-Sormunen, M., \& Lehtinen, E. (2015). Modeling the developmental trajectories of rational number concept (s). Learning and Instruction, 37, 14-20. https://doi.org/10.1016/j.learninstruc.2013.12.004

Meert, G., Grégoire, J., \& Noël, M. P. (2010). Comparing the magnitude of two fractions with common components: Which representations are used by 10-and 12-year-olds? Journal of Experimental Child Psychology, 107(3), 244-259. https://doi.org/10.1016/j.jecp.2010.04.008

Merenluoto, K., \& Lehtinen, E. (2004). Number concept and conceptual change: towards a systemic model of the processes of change. Learning and Instruction, 14(5), 519-534. https://doi.org/10.1016/j.learninstruc.2004.06.016

Moss, J. (2005). Pipes, tubs, and beakers: New approaches to teaching the rational-number system. In Donovan, M. S., \& Bransford, J. D. (Eds.), How students learn: History, math, and science in the classroom (pp. 309-349). Washington DC: National Academies Press.

Moss, J., \& Case, R. (1999). Developing children's understanding of the rational numbers: A new model and an experimental curriculum. Journal for Research in Mathematics Education, 30, 122-147. https://doi.org/10.2307/749607

Ni, Y., \& Zhou, Y. D. (2005). Teaching and learning fraction and rational numbers: The origins and implications of whole number bias. Educational Psychologist,40(1), 27-52. https://doi.org/10.1207/s15326985ep4001 3

Nunes, T., \& Bryant, P. (2008). Rational numbers and intensive quantities: challenges and insights to pupils’ implicit knowledge. Anales de Psicología/Annals of Psychology, 24(2), 262-270.

Obersteiner, A., \& Alibali, M. W. (2018). Are adults biased in complex fraction comparison, and can benchmarks help? In E. Bergqvist, M. Österholm, C. Granberg, \& L. Sumpter (Eds.), Proceedings of the 42nd Conference of the International Group for the Psychology of Mathematics Education (Vol. 3, pp. 427-434). Umeå, Sweden: PME.

Obersteiner, A., Van Dooren, W., Van Hoof, J., \& Verschaffel, L. (2013). The natural number bias and magnitude representation in fraction comparison by expert mathematicians. Learning and Instruction, 28, 64-72. https://doi.org/10.1016/j.learninstruc.2013.05.003

Obersteiner, A., Van Hoof, J., Verschaffel, L., \& Van Dooren, W. (2016). Who can escape the natural number bias in rational number tasks? A study involving students and experts. British Journal of Psychology, 107, 537-555. https://doi.org/10.1111/bjop.12161

Pearn, C., \& Stephens, M. (2004). Why you have to probe to discover what year 8 students really think about fractions. In I. Putt, R. Faragher, \& M. McLean (Eds.), Mathematics education for the third millenium: Towards 2010 (Proceedings of the 27th Annual Conference of the Mathematics Education Research Group of Australasia (pp. 430-437). Sydney, Australia: MERGA.

Resnick, L. B., Nesher, P., Leonard, F., Magone, M., Omanson, S., \& Peled, I. (1989). Conceptual bases of arithmetic errors: The case of decimal fractions. Journal for Research in Mathematics education, 20, 8-27. https://doi.org/10.2307/749095 
Rinne, L. F., Ye, A., \& Jordan, N. C. (2017). Development of fraction comparison strategies: A latent transition $\quad$ analysis. Developmental $\quad$ Psychology, 53(4), https://doi.org/10.1037/dev0000275

Sarstedt, M., \& Mooi, E. (2014). A concise guide to market research. The process, data, and methods using IBM SPSS Statistics. Berlin: Springer.

Schwarz, G. (1978). Estimating the dimension of a model. The Annals of Statistics, 6, 461-464.

Smith, C. L., Solomon, G. E., \& Carey, S. (2005). Never getting to zero: Elementary school students' understanding of the infinite divisibility of number and matter. Cognitive Psychology, 51(2), 101-140. https://doi.org/10.1016/j.cogpsych.2005.03.001

Stafylidou, S., \& Vosniadou, S. (2004). The development of students' understanding of the numerical value of fractions. Learning and Instruction, 14(5), 503-518. https://doi.org/10.1016/j.learninstruc.2004.06.015

Streefland, L. (1991). Fractions in realistic mathematics education: A paradigm of developmental research. Dordrecht, The Netherlands: Kluwer

Torbeyns, J., Schneider, M., Xin, Z., \& Siegler, R. S. (2015). Bridging the gap: Fraction understanding is central to mathematics achievement in students from three different continents. Learning and Instruction, 37, 5-13. https://doi.org/10.1016/j.learninstruc.2014.03.002

Vamvakoussi, X., \& Vosniadou, S. (2004). Understanding the structure of the set of rational numbers: A conceptual change approach. Learning and Instruction, 14(5), 453-467. https://doi.org/10.1016/j.learninstruc.2004.06.013

Vamvakoussi, X., \& Vosniadou, S. (2007). How many numbers are there in a rational numbers interval? Constraints, synthetic models and the effect of the number line. In S. Vosniadou, A. Baltas, \& X. Vamvakoussi (Eds.), Reframing the Conceptual Change Approach in Learning and Instruction (pp. 265-282). Amsterdam, The Netherlands: Elsevier.

Vamvakoussi, X., Christou, K. P., \& Vosniadou, S. (2018). Bridging psychological and educational research on rational number knowledge. Journal of Numerical Cognition, 4(1), 84-106. https://doi.org/10.5964/jnc.v4i1.82

Vamvakoussi, X., Christou, K. P., Mertens, L., \& Van Dooren, W. (2011). What fills the gap between discrete and dense? Greek and Flemish students' understanding of density. Learning and Instruction, 21(5), 676-685. https://doi.org/10.1016/j.learninstruc.2011.03.005

Vamvakoussi, X., Van Dooren, W., \& Verschaffel, L. (2012). Naturally biased? In search for reaction time evidence for a natural number bias in adults. The Journal of Mathematical Behavior, 31(3), 344-355. https://doi.org/10.1016/j.jmathb.2012.02.001

Van Dooren, W., Lehtinen, E., \& Verschaffel, L. (2015). Unraveling the gap between natural and rational numbers. Learning and Instruction, 37, 1-4. https://doi.org/10.1016/j.learninstruc.2015.01.001

Van Hoof, J., Degrande, T., Ceulemans, E., Verschaffel, L., \& Van Dooren, W. (2018). Towards a mathematically more correct understanding of rational numbers: A longitudinal study with upper elementary school learners. Learning and Individual Differences, 61, 99-108. https://doi.org/10.1016/j.lindif.2017.11.010 
Van Hoof, J., Lijnen, T., Verschaffel, L., \& Van Dooren, W. (2013). Are secondary school students still hampered by the natural number bias? A reaction time study on fraction comparison tasks. $\begin{array}{llll}\text { Research in } \quad \text { Mathematics } \quad \text { Education, } & \text { 12(2), }\end{array}$ https://doi.org/10.1080/14794802.2013.797747

Van Hoof, J., Vandewalle, J., Verschaffel, L., \& Van Dooren, W. (2015). In search for the natural number bias in secondary school students' interpretation of the effect of arithmetical operations. Learning and Instruction, 37, 30-38. https://doi.org/10.1016/j.learninstruc.2014.03.004

Van Hoof, J., Verschaffel, L., \& Van Dooren, W. (2015). Inappropriately applying natural number properties in rational number tasks: Characterizing the development of the natural number bias through primary and secondary education. Educational Studies in Mathematics, 90(1), 39-56. https://doi.org/10.1007/s10649-015-9613-3

Vosniadou, S., Vamvakoussi, X., \& Skopeliti, X. (2008). The framework approach to the problem of conceptual change. In S. Vosniadou (Ed.), International Handbook of Research on Conceptual Change (pp. 3-34). Mahwah, NJ: Lawrence Erlbaum. 